\title{
The cat on a hot tin roof? Critical considerations in multilingual language assessments
}

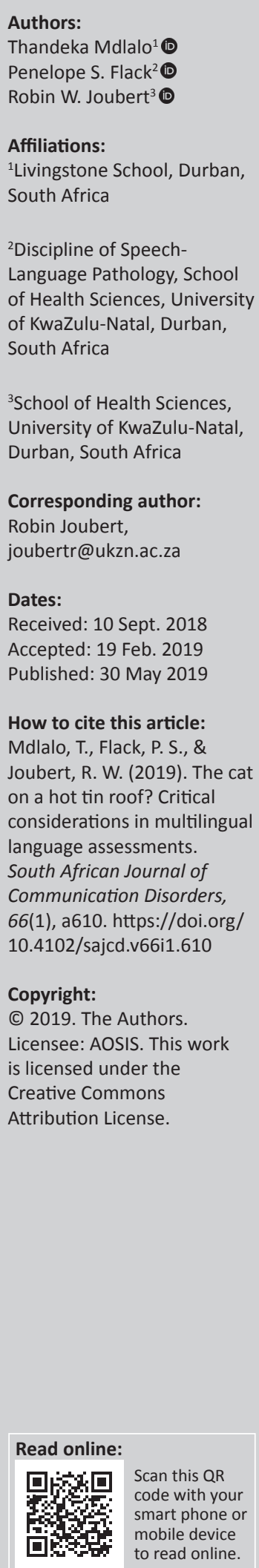

Background: In speech-language pathology (SLP), there is a paucity of resources to provide just and equitable services to South Africa's culturally and linguistically diverse population. Although South Africa is a multilingual country, English remains the dominant language. However, there is limited research on resources for English additional language (EAL) speakers.

Objectives: This article addresses this gap by presenting the results of a critique of a commonly used language screening tool, the Renfrew Action Picture Test (RAPT), on EAL speakers.

Method: This tool is used as an example to broadly critique the use of culturally biased assessment instruments with EAL speakers from an indigenous linguistic and cultural background. It is administered to children who are EAL speakers and then critiqued by the children too. Their voice, often ignored in research, is central to the research. A mixed methods approach is used, including focus groups and test administration. This article is based on the results of the thematic analysis used to closely examine the patterns that emerge.

Results: A key finding is that the cultural and linguistic background of the child assessed cannot be disregarded, as it plays a crucial role in understanding the response of the child. The interpretation of the response of the child to the presented material of the language assessment tool significantly influences the result of the assessment.

Conclusion: The speech language therapist has a responsibility to avoid skewed results based on uninformed interpretation of the response of the child. These findings provide useful insights for clinicians regarding culture-fair assessment.

Keywords: Assessment; cultural and linguistic diversity; English additional language speaker; language dominance; language competence; speech-language pathology.

\section{Introduction and literature review}

The title, the cat on a hot tin roof, draws on a drama, Tennessee William's drama (Holder, 2016; Williams, 1955), whose existentialist message is relevant to the issues argued. This article presents and discusses the results of a study that critically evaluated and interrogated the use of language assessment tools, in their current form, within the South African context. It also provides the guidelines for adaptations of these tools so that they will better accommodate English additional language (EAL) speakers. The term 'EAL speaker' is used in this article to specifically refer to South African multilingual individuals who are non-mother-tongue speakers of English and who are from indigenous language and cultural backgrounds. ${ }^{1}$

The existential message stems from the philosophy that humans are neither mere puppets that exist in the world, nor predestined victims of their conditions in the world. Instead, they are conscious beings who exercise freedom of choice in the decisions that they take in spite of restrictions imposed (Heidegger, 2008). This philosophy is revisited in the 'Discussion' section of the article in relation to the profession speech-language pathology (SLP).

South Africa is a linguistically and culturally diverse country with 11 official languages. The speakers of isiZulu constitute the majority at $22.7 \%$ (Stats SA, 2011). Although there are less than $10 \%$ English mother-tongue speakers, English is a dominant language in the country. As the profession of SLP is a microcosm of the wider SA society, this dominance is reflected within the profession (Mdlalo, Flack, \& Joubert, 2016). The majority of isiZulu mother-tongue speakers are in the province of KwaZulu-Natal, where the research presented was conducted. Although the focus of this article is children who come from the Zulu culture and are isiZulu mother-tongue speakers, issues of culture-fair assessment are broader.

1.Not a homogenous group, there may be inter- and intra-linguistic and cultural variability. 
The problem of culture-fair assessment is not unique to South Africa (Laher \& Cockcroft, 2017; McLeod, 2014), but a global problem that has been identified in regions such as Australia (Ball \& Peltier, 2011), Eastern Europe (Moro, 2008), USA (Hamilton, 2014), New Zealand (Brewer \& Andrews, 2016) and Canada (Thordardottir, 2011). However, the suggestion proposed in the study is especially relevant to the South African context as it is based on African language and cultural experience (Makiwane, Nduna, \& Khalema, 2016).

The use of standardised tests, with EAL populations, in their current form has been criticised both locally and globally, firstly for linguistic bias, secondly, cultural bias and thirdly, disproportionate representation of different language and cultural groups in normative samples (Caesar \& Kohler, 2007; Kathard \& Pillay, 2015; Pierce \& Williams, 2013). The use of English language assessment tools, in their current form, adversely impacts on the appropriate evaluation of individual clients from other culturally diverse backgrounds, thus preventing them from using their own frame of reference (Moro, 2008; Pascoe \& Norman, 2011). These tests are not only inappropriate for use in their current state without adaptation for the South African English mother-tongue speaker, but even more so for the African EAL speaker who is of an indigenous language and cultural background. The speech language therapist (SLT) needs to accommodate the variations in response, which requires an understanding of the South African child's knowledge and experiences, and the language and vocabulary linked to their daily life and cultural practices (Makiwane et al., 2016). These guidelines and principles could be used by language professionals to manage the assessment process and interpretation of findings from EAL speakers in a more accurate, appropriate and equitable manner.

One of the most common tools SLTs use for language screening, for all clients including African EAL speakers who are from an indigenous language and cultural background, is the Renfrew Action Picture Test (RAPT) (Renfrew, 1997). The RAPT is an expressive screening test for language development that was developed by Catherine Renfrew and originally standardised using English mother-tongue speaking British and Irish children between the ages of 3 and 8 years (Renfrew, 1997). Research findings in the survey, referred to the methodology and reflected in Table 1 revealed that the RAPT is one of the most commonly used screening tests for language development by respondents in this survey in South Africa for all clients, including African EAL speakers who are from an indigenous language and cultural background (Mdlalo et al., 2016). Therapists have remarked that the advantage of using the tool is that it is short, easy to administer and cost-effective (Roulstone et al., 2015). In spite of being aware that the screening tool does not accommodate the indigenous language and culture of the African EAL speaker as it is based on Western ${ }^{2}$ culture and experience, thereby reflecting a Western world view, SLTs commented that their use of it and other tests that are not

2.Despite the risk of overgeneralising as the Western culture is not composed of a single, homogeneous set of values, the term 'Western' has been used as reflected in the literature (Miller, 2012). linguistically and culturally relevant to the SA context is influenced by the paucity of appropriate and culturally relevant resources (Barratt, Khoza-Shangase, \& Msimang, 2012; Gxilishe, 2008; McLeod, 2014; Mdlalo et al., 2016).

As the study focused on the African EAL speaker from an indigenous language and cultural background, research into the child's indigenous knowledge system is crucial to ensure that any proposed adaptation is relevant to the daily experiences of the child, and will provide essential information that reflects the child's indigenous world view (Chivaura, 2006). Failure to ensure this could result in an assumption of a language problem which does not exist, and lead to inappropriate recommendations or even intervention (Cofresi \& Gorman, 2004).

\section{Methodology}

The aims of the study were to establish the implications of using a currently favoured language screening tool in South Africa, the linguistic and cultural relevance of this screening tool for isiZulu-speaking children as an example, and how the language screening assessment tool could be adapted to be more linguistically and culturally relevant.

A qualitative approach was used to determine the perspectives of the various groups of participants and to analyse the findings. This provided a relevant framework to illustrate how people drew in-depth meanings from their social actions, background, culture and world view, and how these responses could be interpreted, comprehended and appreciated.

The RAPT served multiple methodological purposes in this study, as reflected in phase 1 in Table 1 . It was used for individual testing of the children to demonstrate differences in interpretation and as an example for discussion in the focus groups with the children.

The article mostly focuses on phase 1, where the participants were 90 children (see Table 1).

TABLE 1: The research data description and data collection methods.

\begin{tabular}{|c|c|c|c|}
\hline Phase & Step & $\begin{array}{l}\text { Data description and } \\
\text { sequence }\end{array}$ & $\begin{array}{l}\text { Method and data } \\
\text { collection Tool }\end{array}$ \\
\hline Preparatory & - & $\begin{array}{l}\text { A descriptive survey via a } \\
\text { nationally posted } \\
\text { questionnaire. } \\
\text { The findings of this phase } \\
\text { of the research are covered } \\
\text { in a separate article } \\
\text { (Mdlalo et al., 2016). }\end{array}$ & $\begin{array}{l}\text { - Survey with SLTS } \\
\text { - Questionnaire }\end{array}$ \\
\hline \multirow[t]{2}{*}{ One } & $\begin{array}{l}\text { Step 1: Test } \\
\text { administered }\end{array}$ & $\begin{array}{l}\text { RAPT administered in } \\
\text { English to all children who } \\
\text { met the selection criteria. }\end{array}$ & $\begin{array}{l}\text { - Administering of test } \\
\text { to children through } \\
\text { individual presentation, } \\
\text { using language } \\
\text { instrument (RAPT), video } \\
\text { and audio recording. }\end{array}$ \\
\hline & $\begin{array}{l}\text { Step 2: Focus } \\
\text { group } 1\end{array}$ & $\begin{array}{l}\text { Conducted in mother- } \\
\text { tongue (i.e. isiZulu) } \\
\text { using pictures in RAPT as } \\
\text { stimulus for discussion. }\end{array}$ & $\begin{array}{l}\text { - Focus group (children) } \\
\text { - Each group with five to } \\
\text { six children } \\
\text { - Ages 6-8 years } \\
\text { - From low SES } \\
\text { - Video and audio } \\
\text { recording input. }\end{array}$ \\
\hline
\end{tabular}

RAPT, Renfrew Action Picture Test; SLT, speech language therapist; SES, socio-economic status. 


\section{Step 1: Individual testing}

Although the administration and scoring manual of the research instrument required that it be scored quantitatively (Renfrew, 1997), in this particular research, it was used qualitatively as it was not used to identify language disorders per se, but was used as a 'case study' to demonstrate the effects of culture and different language upon interpretation of test stimuli. Because it is one of the most commonly used language screening tools in South Africa, the RAPT was used in this study to determine whether there were consistent deviations in the responses from EAL isiZulu-speaking children to the questions on the various picture stimuli. It was applied to the children in the study who were from low socio-economic backgrounds and whose ages ranged from 6 to 8 years exactly as stipulated in Table 1 and the responses were recorded verbatim, as indicated in the test administration manual. A total of 50 children were used for the test administration. These were then interpreted and analysed qualitatively.

Although the cultural and linguistic relevance of this commonly used screening tool was interrogated from four different viewpoints, this article focuses on the perspective of the children who are the target population of the tool. As language assessments are conducted with people who exist within a cultural context, the cultural capital is embedded in language (Blair, 2016; Espinoza-Herold \& González-Carried, 2017; Haneda, 2014; Smith, 2015; Westby, 2009).

This study focused on the relationship between language and culture and adopts an ecological approach to the problem; thus, a conceptual model that encompasses a strong ecological and cultural component was selected, that is, Taylor's (1986) cultural frameworkforviewingnormaland pathological communication.

\section{Step 2: Children's focus group}

A total of 40 children from the isiZulu linguistic and cultural background were divided into focus groups consisting of five to six pupils in each group. Prior to the actual testing, individual test administration piloting was conducted. Piloting of both the test administration and the 'voice of the children' group was beneficial as it acted as a dress rehearsal for the actual test administration and also provided an opportunity to review data collection techniques (Leedy \& Ormrod, 2010). The children's focus group was piloted using a group of 10 children consisting of equal numbers of boys and girls. Problems that were identified were addressed prior to the individual trial-testing and the children's focus group sessions. These included improving the clarity of the questions, ensuring that sufficient rapport was established prior to the individual and group sessions and further clarification regarding which language the children should use in their responses was required.

\section{Profile of the children in the study}

Black, isiZulu mother-tongue speaking children from both urban and rural schools participated in the study. The urban schools selected were ones that are categorised as 'no-fee' paying by government as the majority of the children came from low-income homes (Burger, 2011), and were the children who went to the farm or rural areas during the holidays. Their dual experiences, of both urban and rural environments, were reflected in their responses. In this study, only the urban school was English medium, while the rural schools were isiZulu medium. The children in rural schools were only exposed to English at school or via the media.

As the test was used to screen children, it was integral to this study that the voice of the children be heard (Messiou, 2013). The soliciting of the voice of the children was performed through individual sessions and focus groups. Table 1 summarises the data collection methods and data analysis strategies of the full study.

\section{Ethical consideration}

Ethical clearance for the research (Ethical approval number HSS/115/100) (see Appendix 1) was provided by the University of KwaZulu-Natal Humanities and Social Sciences Research Ethics Committee.

\section{Results}

The findings of the study, that is, individual children assessment and focus groups, were analysed and the emerging patterns discussed. The responses were reviewed, and based on the emerging patterns, the implications these findings had for the speech-language pathology (SLP) profession were explored.

The format used to depict the results was to present each picture from the Renfrew Action Picture (RAPT) and under each picture, the responses from each of the participants. The response was followed by a commentary. The visual stimuli ${ }^{3}$ and responses were categorised into the themes depicted in Table 2.

Interpretation of the patterns emerging and support for the assertions about the African culture and experience were drawn from the literature of various disciplines such as anthropological, psychological, linguistic and sociological writings (Kunnie \& Goduka, 2006; Okon, 2013) that are related

TABLE 2: A table outlining the content of visual stimuli in the Renfrew Action Picture Test.

\begin{tabular}{ll}
\hline Themes & Visual stimuli in RAPT ${ }^{\odot}$ (Speechmark Ltd) \\
\hline 5.1: Human relations and respect & - Girl hugging a teddy bear - Picture 1 \\
& - Kneeling woman helping child - Picture 2 \\
& - Girl falling down the stairs - Picture 6 \\
& - Baby lifted by older girl - Picture 7 \\
- Boy picking up fallen apples - Picture 10 \\
- Dog tied to a pole - Picture 3 \\
- Man riding a horse - Picture 4 \\
- Dog with a crying boy - Picture 9 \\
- Cat with mice - Picture 5 \\
- Cat on the roof of a house - Picture 8 \\
\hline
\end{tabular}

RAPT, Renfrew Action Picture Test.

3.The visual stimuli from the RAPT fourth edition published in 1997 and reprinted in 2010 , were used in the study. The 2010 publication (accessed at the end of the writing of the study) of the RAPT has revised visual stimuli. The content of the visual stimuli of the study) of the RAPT has revised visual stimuli. The content of the visual stimul
has been modernised and also reflects different races. These revisions are noted and acknowledged but do not change the findings and central arguments in this study. 
to the themes emerging in the study. The black African culture, stories, philosophy and traditions have a formidable oral tradition that is reflected in, or is the underlying reason for, some of the practices that may be perceived as different, irrational, unreasonable, purposeless or even primitive when judged and viewed through the Western ${ }^{4}$ lens (Higgs, 2010; Mucina, 2013). Some of the actions or interpretations of the pictures of the participants in the study are embedded in this oral tradition and there may be a paucity of literature on them, for example hugging in black African culture. This paucity of literature presents with numerous difficulties and constraints in the interpretation and translation of the responses because the interpretation of the responses is influenced by language as 'ideas and philosophies created in one language cannot always be adequately translated into another language without losing some meaning because each language speaks to a specific contextual symbolic encoding' (Mucina, 2013, p. 24) because of language translational limitation (Barratt et al., 2012). Mucina's remark illustrates how the process of translating or interpreting across languages can present a challenge to accurate symbolic expression and cultural transmission of ideas and philosophies. When translating, there is an attempt to impose a certain level of resemblance and equivalence in word or concept meaning. However, the interpretation of the word or concept is influenced by factors such as culture, world view and frame of reference of the speaker. The result is what may be regarded as a logical deduction, butmay notberelevant, as the mental representations differ despite the seeming resemblance and coincidences in meaning. An example is the root or stem in isiZulu, -nde, encompassing both the meanings and associations linked to the words tall and long in English and often presents with many misinterpretations in conversations when directly translated. Another example is use of the word 'checkers' to refer to the bag (in picture card 10). In townships, any grocery plastic bag is commonly referred to as a 'checkers'. These examples show that words that have a meaning that may be clear for an English First Language (L1) speaker may not necessarily have the same meaning from the perspective of an L2 speaker. They may be ambiguous based on how the L2 speaker has experienced their being used, that is, interlingual ambiguity.

These restrictions manifest in the analysis of the responses. For example, the use of clan names between communicators may represent the same level of intimacy as hugging and yet, despite the seeming resemblance to nicknames in Western culture, not have the same mental representation or meaning.

Picture card 8 on the RAPT (see Figure 1) has been selected in this article to illustrate the argument, as it was unanimously the most controversial picture. The controversy was around the black cat and how it is perceived in the black community (Mutwa, 2003). A black cat is usually associated with witchcraft and negativity. As a pet, it is to protect the home by killing unwanted pests, such as snakes and mice (Mutwa, 2003). The concept of rescuing a black cat was regarded by most focus group participants as inviting danger. The responses from the children (see Tables 3 and 4) clearly indicated that the security

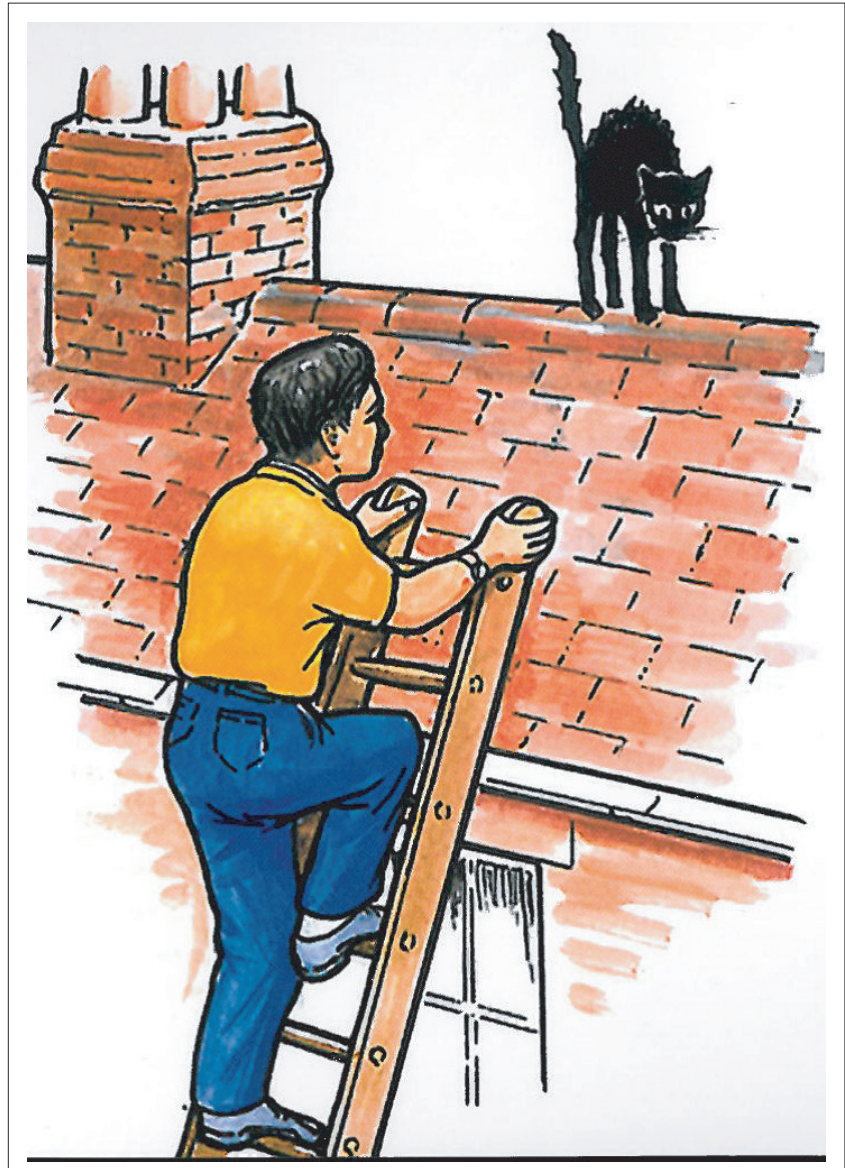

Source: Renfrew, C. (1997). The Renfrew action picture test (4th edn.). London: Speechmark Publishing

FIGURE 1: Illustrating picture card 8 from the RAPT (1997) ( ${ }^{\circ}$ Speechmark Ltd).

TABLE 3: Some results of the voice of the children for each picture.

Picture Summary of children's responses Relevance for SLT or themes emerging

1 Referred to the toy as teddy bear or - Differences in perception of doll; did not mention hugging but demonstration of intimacy, for rather quieting and comforting the example hugging. baby 'shushuzela'. Rural children - Despite the universality of concept frequently mentioned racial of play, the form it takes in different differences. communities and culture differs.

2 Highlighted the mother kneeling; - Differences in perception of helping of a child to dress associated child-child versus child-adult with a younger child. It is culturally relations or roles, reflected in inappropriate for an adult to kneel responses. for a child in the Zulu culture.

3 They perceived the dog as for Differences in perception of roles protection. It was seen as a pet but of animals reflect. they clarified that it was not to be stroked or stay in the house.

4 Rural children could not relate to the Exposure affects responses horse as depicted in sport in the picture, did not know the concept of a jockey or saddle; saw it as a useful animal that can save one from danger as used in own context.

SLT, speech language therapist.

of the man climbing the ladder was at stake. Therefore, in the following phase of the study, the picture was adapted to be more culturally appropriate and the black cat on the roof was replaced by a ball that was to be 'fetched' from the roof of the house (Mdlalo, 2013).

It was interesting that the concepts of witchcraft and traditional African values are usually mostly associated with the rural areas (Durrheim, Mtose, \& Brown, 2011), and yet it was the 
TABLE 4: Children's responses and reasons for adaptation of the Renfrew Action Picture Test expected responses.

\begin{tabular}{|c|c|c|}
\hline $\begin{array}{l}\text { Expected response } \\
\text { in RAPT }\end{array}$ & $\begin{array}{l}\text { Actual response of } \\
\text { children }\end{array}$ & Reasons for adaptation \\
\hline $\begin{array}{l}\text { Climb up or on, go } \\
\text { up to, try to go up, } \\
\text { ladder, get, fetch, } \\
\text { reach, save, rescue, } \\
\text { cat, kitten, pussy, } \\
\text { on or off, down } \\
\text { from or off, from } \\
\text { roof, top of house }\end{array}$ & $\begin{array}{l}\text { Climb up or on, go up, try } \\
\text { to go up, ladder, get, cat } \\
\text { on or off, from roof, roof, } \\
\text { chase, fix, step or stairs, } \\
\text { take, catch, run away, } \\
\text { man, get, catch, father, } \\
\text { boy, up, cat, top }\end{array}$ & $\begin{array}{l}\text { - Words not used were 'reach', } \\
\text { 'save', 'rescue' and 'pussy'. } \\
\text { 'save' and 'rescue' are linked } \\
\text { to the perception of the cat as } \\
\text { being in danger } \\
\text { - South African English, the } \\
\text { word 'pussy' is not usually } \\
\text { used in isolation } \\
\text { - Although 'ladder' is a } \\
\text { commonly used word in } \\
\text { English, colloquially, African } \\
\text { language speakers have often } \\
\text { replaced it with the word } \\
\text { 'steps' }\end{array}$ \\
\hline
\end{tabular}

RAPT, Renfrew Action Picture Test.

urban children who did not like the picture because of these associations. The rural children's fear of a cat was similar to their fear of any other potentially dangerous animal and was not for culturally related reasons, whereas urban children's aversion to the black cat as a dangerous animal was more reflective of the cultural view. This response suggests that assumptions that are often associated with the distinction between urban and rural communities are not always accurate. This finding shows that speech-language therapists (SLTs) should be cautious of using typical stereotypes pertaining to urban and rural communities (Durrheim et al., 2011).

The responses of the children illustrate that verbal associations with the picture or words may be different from those expected by the SLT, as associations are linked to experience, background and culture. Verbal associations are thus linked to sociolinguistic factors.

The responses from the children were often characterised by pregnant pauses or slow responses. The detection of the words in the question and planning a response based on the detected word is a complex process when the question is not in the L1. This slowness in word detection may be misinterpreted as word-retrieval or word-finding problems. De Rauville (2004) argues that in EAL speakers, certain behaviours may seem to be word-finding errors, such as word-searching, whereas these errors may be a reflection of their limited semantic knowledge in the second language (De Rauville, 2004, p.17) and therefore not a language pathology.

\section{Discussion}

The responses from the children accentuate numerous critical issues that the SLT needs to be aware of in working with culturally diverse populations.

Apart from the theory, the philosophical lens through which the SLT views and interprets this information will determine how it is used and whether justice is served (Arias \& Friberg, 2017; Fricker, 2007; Morreira, 2017). If the SLT uses his or her own frame of reference to interpret, the picture presented may still be skewed. Often, the perception of the dominant culture is used as a basis for whether it is pathological or not. In South Africa, the Western culture of the English L1 speaker is often part of this dominant culture and Western
TABLE 5: Linguistic differences that may be misconstrued as part of a syntactic disorder.

\begin{tabular}{ll}
\hline Utterance & Explanation \\
\hline The man, he rides a horse & $\begin{array}{l}\text { The isizulu concordial structure } \boldsymbol{U} \text { muntu } \boldsymbol{U} \text { gibela } \\
\text { superimposed }\end{array}$ \\
The lady, he walks & There are no gender grammatical structures in isizulu \\
\hline
\end{tabular}

standards become the basis and bias for the decision as to whether a communication difference is a communication difficulty or difference. The examples above of children's utterances from pictures cards 4 and 10 provide an illustration of linguistic differences that may be misconstrued as part of a syntactic disorder but influenced by the L1 (Table 5).

Language transfer occurs when the characteristics of one language affect those of another. These may occur at a morphological, syntactic, semantic or pragmatic level (Myers-Scotton, 2006). An understanding of the structure of isiZulu as a language will help to make sense of these language differences, which may be depicted as errors because of misinterpretation or misunderstanding

Another illustration from the picture card 8 is the use of the word ladder. Although the direct translation of the word is ileli, in practice it is commonly used interchangeably with amastepisi (steps) and this was reflected in the children's responses. An SLT who has no understanding of this frame of reference will regard the steps as inaccurate.

Based on the existentialist message in the introduction, SLTs are free to choose to use the client's frame of reference despite the challenges of limited knowledge and resources that may exist. Cultural sensitivity will help the SLT to understand the responses and interpretation of responses that may seem inappropriate or irrelevant.

Within the profession, both globally and locally, there is consensus on the need to transform the current paucity of material and guidelines on the assessment and management of culturally diverse populations. Research, assessment tools and profiles have been developed by professionals and tertiary institutions in an attempt to bridge this gap (Pascoe \& McLeod, 2016; Singh et al., 2015; Van der Merwe \& Roux, 2014). There is, however, an acknowledgement that, despite these attempts, what has been produced to resolve this social reality is a drop in the ocean in terms of the needs within the profession (Khoza-Shangase \& Mophosho, 2018).

Anecdotal evidence suggests that there is a practice that, despite the extremely limited resources available for assessment of the EAL speaker, the tools that exist, for example South African Language Assessment (SALA - in all South African languages) and Test of Ability to Explain for Zulu Speaking Children (TATE-ZC), are not used. There has been very little research that has tapped into this issue in South Africa. In this study, some of the changes made to the research instrument, the RAPT, based on the responses of the participants, have already been made to other tests 
(Solarsh, 2001; Solarsh \& Alant, 2006), but these changes appear not to have been implemented in the use of these tests. They are still used in their original form, not taking into account the research-based adaptations for multicultural clients. The question that arises is whether SLTs are guilty of what critical theorists would describe as 'social oppression' by ignoring more culturally and linguistically appropriate resources for assessment. If the answer is positive, the critical theorists (Han \& Price, 2015) propose a process of assisting them to become aware of the manner in which this social oppression operates through the process of conscientisation, that is, a process of creating awareness of another social reality, thereby helping to free them from social oppression.

A critical theorist, drawn from the field of education, who advances this argument competently, is Paulo Freire. The process of conscientisation is also central to his educational theory of radical social change (Freire, 2000), which focuses on the root causes of social and political problems rather than the symptoms, to allow for the planning of strategies to address them. Freire argues that critical consciousness is essential to reassess the types of ideas, contexts and relationships that are typically 'taken for granted' or accepted as the norm prior to ascertaining the root causes of social oppression (Freire, 2000). Furthermore, he argues that authentic engagement with people you are committed to requires constant self-reflection.

Based on Freire's argument, a question that arises is whether SLTs are constantly self-reflecting on how to best engage with the challenge of EAL speakers or are complacent with the current scenario of the scarcity of appropriate and culturally relevant assessment instruments for EAL speakers from indigenous linguistic and cultural backgrounds. Freire regards such a scenario as reflecting a degree of complicity. This means that SLTs may be aware of the gaps or contradictions but choose to turn a blind eye to them.

From an SLT perspective, we argue that conscientisation forms part of the solution. We believe that this process is long overdue and would play a significant role in addressing the social injustices of South Africa's past (Kathard \& Pillay, 2013). The continued use of tests on EAL speaking children that are normed on predominantly English-speaking UK or USA populations in their current form can present the SLT with inaccurate findings that may be used to determine the future of the children assessed (Arias \& Friberg, 2017; Williams \& McLeod, 2012). The future of these children therefore rests on the use of the RAPT and any other language assessment test in a culturally and linguistically relevant manner. Furthermore, the SLT will be able to conduct a comprehensive assessment and make an informed decision based on a holistic picture of the child's competencies. The SLP profession has a responsibility to conscientise itself (Kathard \& Pillay, 2013) in a culturally and linguistically relevant manner regarding the use of the currently available tools. Practically, this entails SLTs understanding the language or culture of the client, understanding bilingualism and second language acquisition.

\section{Conclusion}

The results of the study show that the heterogeneous nature of the South African population, especially pertaining to language and culture, places certain responsibilities on the SLT to ensure ethical, just and moral assessments. It is pivotal to acknowledge that heightened consciousness and reflection form part of this process. As each SLT is an intentional being (Heidegger, 2008), this process cannot be a tacit one, but should be conscious and active as it has implications for the extent to which the SLP profession can continue to engage in transformation that will result in just and equitable service provision for all the people of the country irrespective of colour, race, creed, culture, religion or gender (Brewer \& Andrews, 2016; Espinoza-Herold \& González-Carried, 2017). A collaborative effort by private, public and tertiary institutions is crucial for the success of this transformation. Despite the intimidating nature of the process, we do not have the option to surrender and allow frustration to dictate the direction of transformation. As SLTs, we dare not to define ourselves by our external circumstance as we are not at the mercy of the limitations linked to diversity but can collaboratively, consciously and reflexively explore the alternatives as we celebrate this diversity.

\section{Acknowledgements Competing interests}

The authors declare that they have no financial or personal relationships that may have inappropriately influenced them in writing this article.

\section{Author's contributions}

This article presents an aspect of T.M.'s PhD, which was supervised by P.S.F. and R.W.J. The article was drafted by T.M., with input from both P.S.F. and R.W.J.

\section{References}

Arias, G., \& Friberg, J. (2017). Bilingual language assessment: Contemporary versus recommended practice in American schools. Language, Speech, and Hearing Services in Schools, 48(1), 1-15. https://doi.org/10.1044/2016_LSHSS-15-0090

Ball, S., \& Peltier, J. (2011). Cultural safety, relevance and effectiveness of speech and language services to indigenous children, 27 April 2011. Montreal: SpeechLanguage and Audiology Canada (CASLPA).

Barratt, J., Khoza-Shangase, K., \& Msimang, K. (2012). Speech-language assessment in a linguistically diverse setting: Preliminary exploration of the possible impact of informal 'solutions' within the South African context. South African Journal of Communication Disorders, 59(1), 34-44. https://doi.org/10.7196/sajcd.51

Blair, A. (2016). Academic uses of language (re)defined: A case of emergent bilinguals engaging in languages and literacies in and outside of school. Linguistics and Education, 35, 109-119. https://doi.org/10.1016/j.linged.2016.07.003

Brewer, K., \& Andrews, W. (2016). Foundations of equitable speech-language therapy for all: The Treaty of Waitangi and Māori health. Speech, Language and Hearing, 19(2), 87-95. https://doi.org/10.1080/2050571X.2015.1122876

Burger, D. (2011). South Africa Year Book 2010/11 (18th edn.). Johannesburg: GCIS

Caesar, L. G., \& Kohler, P. D. (2007). The state of bilingual based school assessment: Actual practice vs recommended guidelines. Language, Speech and Hearing Serices in Schools, 38, 190-200. Retrieved from Ishss.asha.org

Chivaura, V. G. (2006). African indigenous worldviews and ancient wisdom: A conceptual framework for development in Southern Africa. In J. Kunnie, \& N. I. Goduka (Eds.), Indigenous peoples' wisdom and power: Affirming our knowledge through narratives (pp. 213-224). Aldershot: Ashgate Publishing Limited.

Cofresi, N. I., \& Gorman, A. (2004). Testing and assessment issues with SpanishEnglish Bilingual Latinos. Journal of Counselling and Development, 82(1), 99-106. https://doi.org/10.1002/j.1556-6678.2004.tb00290.x 
De Rauville, I. (2004). Current practice for word-finding difficulties by speech-language therapists in South African remedial schools. Master's Thesis. Durban: University of KwaZulu-Natal.

Durrheim, K., Mtose, X., \& Brown, L. (2011). Race trouble-race, identity and inequality in post-apartheid South Africa. Durban: University of KwaZulu-Natal Press.

Espinoza-Herold, M., \& González-Carried, R. (2017). Issues in Latino education: Race, school culture and the politics of academic success. New York: Routledge.

Freire, P. (2000). Pedagogy of the oppressed: 30th anniversary edition. London: Continuum

Fricker, M. (2007). Epistemic injustice: Power and the ethics of knowing. Oxford: Oxford University Press.

Gxilishe, S. (2008). African languages, linguistics and child speech and speech pathology-the connection. Per Linguam: A Journal of Language Learning $=$ Per Linguam: Tydskrif vir Taalaanleer, 24(2), 75-87.

Stat SA. (2011). Government census 2011. Retrieved from http://www.statssa.gov.za/.

Hamilton, M. B. (2014). 'If there's more than one bus you say...': Cultural-linguistic mismatch within the context of teacher-child interactions. Doctoral Early Research Project. University of Illinois at Urbana-Champaign.

Han, E. J., \& Price, P. G. (2015). Uncovering the hidden power of language: Critical race theory, critical language socialization and multicultural families in Korea. Journa of Intercultural Communication, 44(2), 108-131. https://doi.org/10.1080/174757 59.2015.1028427

Haneda, M. (2014). From academic language to academic communication: Building on English learners' resources. Linguistics and Education, 26, 126-135. https:// doi.org/10.1016/j.linged.2014.01.004

Heidegger, M. (2008). Basic writings. London: HarperPerennial.

Higgs, P. (2010). Towards an indigenous African epistemology of community in education research. Procedia - Social and Behavioral Sciences, 2(2), 2414-2421. https://doi.org/10.1016/j.sbspro.2010.03.347

Holder, R. (2016). Making the lie true: Tennessee Williams's cat on a hot tin roof and truth as performance. The Southern Quarterly, 53(2), 77-93. https://doi. org/10.1353/soq.2016.0007

Kathard, H., \& Pillay, M. (2013). Promoting change through political consciousness: A South African speech-language pathology response to the World Report on Disability. International Journal of Speech-Language Pathology, 15(1), 84-89. https://doi.org/10.3109/17549507.2012.757803

Kathard, H., \& Pillay, M. (2015). Decolonising health professionals' education: Audiology and speech therapy in South Africa. African Journal of Rhetoric: Transitions and Transformaative Rhetoric, 17, 193-227.

Khoza-Shangase, K., \& Mophosho, M. (2018). Language and culture in speechlanguage and hearing professions in South Africa: The dangers of a single story. South African Journal of Communication Disorders, 65(1), 1-7. https://doi. org/10.4102/sajcd.v65i1.594

Kunnie, J., \& Goduka, N. (Eds.). (2006). Indigenous people's wiisdom and power Affirming our knowledge through narratives. England: Ashgate Publishing Ltd.

Laher, S., \& Cockcroft, K. (2017). Moving from culturally biased to culturally responsive assessment practices in low-resource, multicultural settings. Professit Psychology: Research and Practice, 48(2), 115-121. https://doi.org/10.1037/ pro0000102

Leedy, P., \& Ormrod, P. D. (2010). Practical research: Planning and design (9th edn.). New Jersey: Pearson Education International.

Makiwane, M., Nduna, M., \& Khalema, N. E. (2016). Children in South African families: Lives and times. Newcastle: Cambridge Scholars Publishing.

McLeod, S. (2014). Resourcing speech-language pathologists to work with multilingual children. International Journal of Speech-Language Pathology, 16(3), 208-218. https://doi.org/10.3109/17549507.2013.876666

Mdlalo, T. (2013). The use of an English Language Assessment Test on South African English Additional Language (EAL) speakers from an indigenous language and cultural background: A critical evaluation. Doctoral Dissertation. University of KwaZulu-Natal.

Mdlalo, T., Flack, P., \& Joubert, R. (2016). Are South African speech-language therapists adequately equipped to assess English Additional Language (EAL) speakers who
are from an indigenous linguistic and cultural background? A profile and are from an indigenous linguistic and cultural background? A profile and Disorders, 63(1), Art. \#130, 5 pages. https://doi.org/10.4102/sajcd.v63i1.130
Messiou, K. (2013). Using student's voices to confront marginalisation in schools: A pathway toway towards inclusion. Paper presented at the SAALED: Dimantling pathway toway towards inclusion. Paper presented at the SAALED: Dimantling
exclusion to enable inclusion, Johannesburg, Wits Education Department, 4-6 July 2013.

Moro, M. R. (2008). Transcultural issues for children and parents in a changing world. Paper presented at the Istanbul. France. Retrieved from http://www.transculturalclinic.org/pdf_IACAPAP_keynotelecturepdf.

Morreira, S. (2017). Steps towards decolonial higher education in southern Africa? Epistemic disobedience in the humanities. Journal of Asian and African Studies, 52(3), 287-301. https://doi.org/10.1177/0021909615577499

Mucina, D. D. (2013). Ubuntu orality as a living philosophy. The Journal of Pan African Studies, 6(4), 18-35.Mutwa, C. (2003). Zulu Shaman: Dreams, prophecies and mysteries. Rochester: Destiny Books.

Myers-Scotton, C. (2006). Multiple voices: An introduction to bilingualism. Victoria: Blackwell Publishing.

Okon, E. E. (2013). Distortion of facts in western ethnographic study of African religion, culture and society. International Journal of Asian Social Science, 3(1), 92-101.

Pascoe, M., \& McLeod, S. (2016). Cross-cultural adaptation of the intelligibility in context scale for South Africa. Child Language Teaching and Therapy, 32(3), context scale for South Africa. Child Language Teachin
327-343. https://doi.org/10.1177/0265659016638395

Pascoe, M., \& Norman, V. (2011). Contextually-relevant resouces in speech-language therapy and audiology in South Africa: Are there any?. South african Journal of Communication Disorders, 58(1), 2-5. https://doi.org/10.4102/sajcd.v58i1.35

Pierce, W. M., \& Williams, C. (2013). The cultural appropriateness and diagnostic usefulness of standardized language assessments for Indigenous Australian children. International Journal of Speech-Language Pathology, 15(4), 429-440. https://doi.org/10.3109/17549507.2012.762043

Renfrew, C. (1997). The renfrew action picture test (4th edn.). London: Speechmark Publishing.

Roulstone, S. E., Marshall, J. E., Powell, G. G., Goldbart, J., Wren, Y. E., Coad, J. ... Coad, R. A. (2015). Evidence-based intervention for preschool children with primary speech and language impairments: Child Talk - an exploratory mixedmethods study. Southampton (UK): NIHR Journals Library; 2015 Aug. (Programme Grants for Applied Research, No. 3.5.) Appendix 33, Rationale behind speech and language therapists' decisions to use assessment tools. Retrieved from https:// www.ncbi.nlm.nih.gov/books/NBK311171/.

Singh, S., Booth, A., Choto, F., Gotlieb, J., Robertson, R., Morris, G., \& Mauff, K. (2015) New graduates' perceptions of preparedness to provide speech-language therap services in general and dysphagia services in particular. South African Journal of Communication Disorders, 62(1), 1-8. https://doi.org/10.4102/sajcd.v62i1.110

Solarsh, B. (2001). Verbal solutions of rural Zulu-speaking children to problems encountered in everyday life. Unpublished doctoral thesis, University of Pretoria, Pretoria.

Solarsh, B., \& Alant, E. (2006). The challenge of cross-cultural assessment - The test of ability to explain for Zulu-speaking children. Journal of Communication Disorders, 39(2), 109-138. https://doi.org/10.1016/j.jcomdis.2005.11.002

Smith, L. E. (2015). English as as international language No room for linguistic chauvunism. Journal of English as a Lingua Franca; Berlin, 4(1), 165-171.

Taylor, O. (1986). Nature of communication disorders in culturally and linguistically diverse populations. San Diego, CA: College-Hill Press.

Thordardottir, E. (2011). Bilingualism: Normal Development and Clinical Intervention 27 April 2011. Montreal: Speech-Language and Audiology Canada (CASLPA).

Van der Merwe, A., \& Roux, M. L. (2014). Idiosyncratic sound systems of the South African Bantu languages: Research and clinical implications for speech-language pathologists and audiologists. South African Journal of Communication Disorders, 61(1), 8 pages. https://doi.org/10.4102/sajcd.v61i1.86

Westby, C. (2009). Considerations in working successfully with culturally/lingistically diverse families in assessment and intervention of communication disorders. Seminars in Speech and Language, 30(4), 279-289. https://doi.org/10.1055/ s-0029-1241725

Williams, T. (1955). Cat on a hot tin roof. New York: Signet.

Williams, C., \& McLeod, S. (2012). Speech-language pathologists' assessment and intervention practices with multilingual children. International Journal of Speech-
Language Pathology, 14(3), 292-305. https://doi.org/10.3109/17549507.2011. Language
636071 